\title{
Pushing the frontier of endoscopic submucosal dissection in the management of colorectal lesions
}

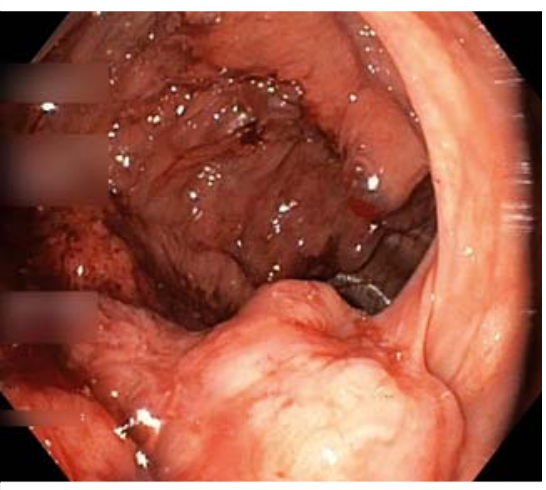

> Fig. 1 Laterally spreading tumor of the granular nodular mixed type (Paris endoscopic classification $0-\mathrm{Il} \mathrm{a}+\mathrm{Is}$ ) extending from the pectinate line to the distal sigmoid colon.

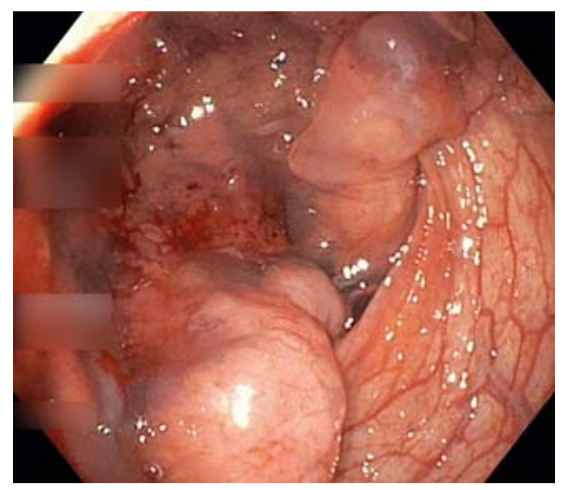

- Fig. 2 Exudative superficial neoplastic colorectal lesion involving $70 \%$ of the luminal circumference.

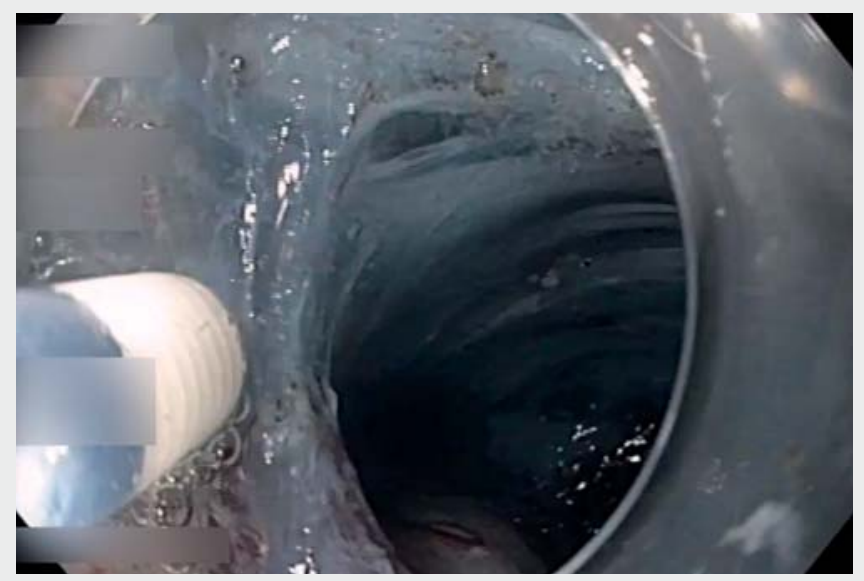

Video 1 Endoscopic submucosal dissection of an extensive superficial neoplastic colorectal lesion in a 41-year-old male with familial adenomatous polyposis.

A 41-year-old man with familial adenomatous polyposis (FAP) recommended for prophylactic colectomy with ileorectal anastomosis was proposed for endoscopic submucosal dissection (ESD) of a superficial neoplastic colorectal lesion ( Fig. 1, \Fig.2). The lesion extended from the pectinate line to the distal sigmoid colon and involved $70 \%$ of the luminal circumference. After thorough endoscopic evaluation with virtual chromoendoscopy, no evidence of invasive disease was found ( $\mathbf{F i g . 3}$ ).

ESD was technically demanding owing to lesion size and extension ( $\vee$ Video 1$)$. En bloc resection was achieved within a total procedure time of 510 minutes. Minor intraprocedural bleeding occurred and was adequately controlled with vessel coagulation. The excised specimen

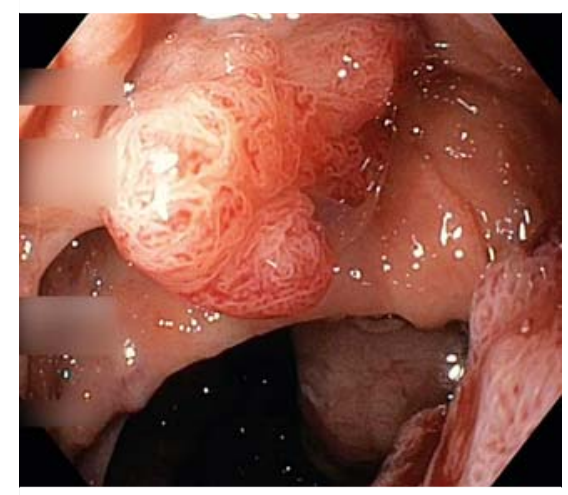

- Fig. 3 No endoscopic signs of invasive cancer (vessel and surface pattern type 2B according to the classification of the Japan NBI Expert Team).

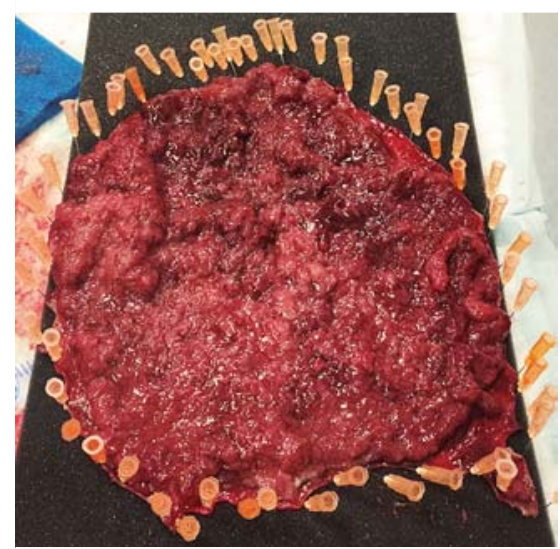

- Fig. 4 Stretching and pinning of the resected lesion; dimensions: $238 \times 215 \mathrm{~mm}$ (maximum length of $270 \mathrm{~mm}$ ).

measured $238 \times 215 \mathrm{~mm}$, with a maximum length of $270 \mathrm{~mm}$ ( $\mathbf{F i g}$. 4). Histopathology confirmed $\mathrm{RO}$ resection of a traditional serrated adenoma with lowgrade and focal high-grade dysplasia.

Endoscopic management of rectal lesions is feasible in FAP, allowing selected patients to avoid proctectomy as long as intensive endoscopic surveillance of the residual rectum is performed [1,2]. Nowadays ESD is frequently used for the resection of colorectal lesions, including 
rectal remnant polyps in FAP [3,4]. However, extensive lesions can be challenging for the endoscopist owing to the loss of orientation caused by rolling of the mucosal flap and the progressive fall of the resected lesion into the lumen. This procedure turned out to be more complex than initially perceived. The extreme effort of the endoscopist allowed sparing of the rectum and consequently improved the quality of life of a patient who would otherwise have been proposed for a proctocolectomy. Therefore, albeit a time-consuming strategy, ESD seems a reasonable approach for the management of exceedingly large colorectal lesions. As more Western endoscopists gain experience in ESD, FAP patients who are candidates for rectal sparing should not be managed with proctocolectomy unless endoscopic management is considered unfeasible.

Endoscopy_UCTN_Code_TTT_1AQ_2AD

\section{Competing interests}

The authors declare that they have no conflict of interest.

\section{The authors}

André Mascarenhas ${ }^{1} \stackrel{\oplus}{\text {, Rui Mendo }}{ }^{1} \stackrel{\oplus}{\text {, Pedro }}$ Barreiro $^{1,2}$, Cristina Chagas ${ }^{1}$

1 Department of Gastroenterology, Centro Hospitalar de Lisboa Ocidental EPE Hospital de Egas Moniz, Lisbon, Portugal

2 Department of Gastrenterology, Hospital Lusíadas Lisboa, Lisbon, Portugal

\section{Corresponding author}

\section{André Mascarenhas, MD}

Department of Gastroenterology, Centro Hospitalar de Lisboa Ocidental, Hospital de Egas Moniz, Rua da Junqueira 126 , 1349-019 Lisbon, Portugal andremascarenhasmd@gmail.com

\section{References}

[1] Takeshita E, Enomoto T, Saida Y. Alternative treatments for prophylaxis of colorectal cancer in familial adenomatous polyposis. J Anus Rectum Colon 2017; 1: 74-77

[2] Syngal S, Brand RE, Church JM et al. ACG Clinical Guideline: Genetic Testing and Management of Hereditary Gastrointestinal Cancer Syndromes. Am J Gastroenterol 2015; 110: 223-263

[3] Pimentel-Nunes P, Dinis-Ribeiro M, Ponchon T et al. Endoscopic submucosal dissection: European Society of Gastrointestinal Endos- copy (ESGE) Guideline. Endoscopy 2015; 47 : 829-854

[4] Ishii N, Akiyama H, Suzuki K et al. Endoscopic submucosal dissection for the complete resection of the rectal remnant mucosa in a patient with familial adenomatous polyposis. ACG Case Rep J 2016; 3: 172-174

Bibliography

Endoscopy 2022; 54: E530-E531

DOI $10.1055 / \mathrm{a}-1662-4813$

ISSN 0013-726X

published online 25.10.2021

(c) 2021. Thieme. All rights reserved.

Georg Thieme Verlag KG, Rüdigerstraße 14, 70469 Stuttgart, Germany

\section{ENDOSCOPY E-VIDEOS}

https://eref.thieme.de/e-videos

口回 Endoscopy E-Videos is an open access online section, 回: reporting on interesting cases and new techniques in gastroenterological endoscopy. All papers include a high quality video and all contributions are freely accessible online. Processing charges apply (currently EUR 375), discounts and wavers acc. to HINARI are available.

This section has its own submission website at https://mc.manuscriptcentral.com/e-videos 